https://doi.org/10.48009/1_iis_2010_309-318

\title{
BEYOND THE IMPACT FACTOR: UPDATES ON A CITATION STUDY FOR INFORMATION TECHNOLOGY JOURNALS
}

Kara Gust Rawlins, Michigan State University, gustk@msu.edu

Dale D. Gust, Central Michigan University, gust1dd@ cmich.edu

\begin{abstract}
Citation data for journals continues to be a prominent tool for evaluating scholarly journals in various fields of study, although new factors play important roles in assessing its validity and importance. This paper will build upon a previous citation study for information technology/computer information systems journals, with special attention to the Journal of Computer Information Systems. It will analyze how ISI's Journal Citation Reports traditionally measures a journal's impact in its disciplines, with special attention to how the Journal of Computer Information Systems has increased its impact factor over the past several years. It will also discuss new implications such as how Google Scholar and other information vendors are now providing citation data that should also be considered when analyzing the impact of a journal in its field.
\end{abstract}

Keywords: citation analysis, journal citation reports, information technology, impact factors, Google Scholar

\section{INTRODUCTION}

Since Garfield's discourse on the need for a systematic way of measuring journal citations and their impact almost 40 years ago, the journal impact factor has played an extensive role in affecting the network of scholarly communication and the emphasis placed on publishing in particular journals [3]. It has also dramatically affected the perceived importance of certain journals and disciplines to the field of scholarly publishing.

The collection of citation data was first established by the Institute for Scientific Information (ISI) and has been almost exclusively gathered by them ever since. It began its statistical tabulation of citations in journals across the sciences and social sciences with its publications of Science Citation Index and Social Sciences Citation Index in 1971. "By gathering journal references, ISI was also able to produce a number of statistical measures of journals in its exclusive Journal Citation Reports (JCR), providing a way for scholars, librarians, and publishers to evaluate the impact of a journal in its own discipline or across disciplines based upon a number of criteria" [4]. ISI continues to provide online subscription access to JCR and its other citation indexes through its Web of Knowledge database.

For years, JCR has been the recognized authority on analyzing citation data to establish a journal's influence and dominance in the field of scholarly literature, although certain other databases are now beginning to challenge that conception. This paper will explore JCR's primary statistical calculationthe impact factor, along with a few other influencing factors. It will build upon a previous citation study for information technology journals, with special attention to the Journal of Computer Information Systems: Gust, K. (2005). Evaluating the impact factor: a citation study for information technology journals, Issues in Information Systems, 7(2), 197203. This study will compare data from 2003 to 2007 to see what changes, if any, have occurred among information technology/computer information systems journals and their impact factors and other rankings. It will also analyze new databases that are challenging ISI's dominance of citation analysis, include Google Scholar.

\section{JCR DATA FOR COMPUTER INFORMATION SYSTEMS JOURNALS: 2003-2007}

In 2005, an exploration of selected computer information systems journals was provided with specific analysis of the Journal of Computer Information Systems [4]. The following section will review that analysis and examine new data from 2007. It will provide a review of which citation data is collected by ISI and how it is calculated, with a comparison among information technology journals, and more specifically computer information systems (CIS) journals. Please note that citation data for the Journal of Computer Information Systems (JCIS) was not available at the time of this study for 2008-2010, so the latest data being referenced is from the 2007 Science Edition of Journal Citation Reports (JCR). 


\section{The Impact Factor Revisited}

The journal impact factor (IF) is by far the most dominant measure of a journal's performance and impact in its field. "It is a measure of the frequency with which the average article in a journal has been cited in a particular year...and is calculated by dividing the number of citations in the current year (2003) to articles published in the two previous years (e.g., 2001-2002) by the total number of articles published in the two previous years (e.g., 20012002)" [4]. Tables 1 and 2 offer a comparison of the impact factor calculation of JCIS in 2003 versus 2007.

From 2003 to 2007 , the IF of JCIS rose from 0.080 to 0.528 - a $560 \%$ increase. Based upon the numbers alone, it is evident that the great increase in cites to recent articles was the ultimate reason the impact factor rose so extensively. Even though the number of recent articles decreased, the number of recent articles cited in 2003 versus 2007 increased by $470 \%$.

In comparison to other CIS journals, in 2005, JCIS was ranked $77^{\text {th }}$ in terms of impact factor; in 2007, it was ranked $65^{\text {th }}$. However, the number of journals in this category also increased from 78 to 92 over the four year span, so JCIS has made even more progress since it is being compared against a greater number of journals. Table 3 shows a comparison of the same CIS journals analyzed by Gust in 2005 and their rankings. All journals are selected from the COMPUTER SCIENCE, INFORMATION SYSTEMS category in the 2003 and 2007 Science Edition(s) of Journal Citation Reports.

As shown in Table 3, there is definite movement in the last four years among the top three journals in 2003 versus 2007. VLDB Journal is the only one remaining from 2003 in the top three, while $A C M$ Transactions on Information Systems and IEEE Network fell 10 and 20 places respectively. MIS Quarterly made excellent gains and moved up from ninth to first place. Journal of Web Semantics was only first published in 2003 and has promptly worked its way up to third place already in the IF rankings.

\section{Impact Factor Comparisons among CIS Journals}

As previously discussed in 2005, there are many considerations to explore when looking at the impact factor. "When comparing journals even within one discipline it is important to consider a number of other factors such as strength and size of the publishing body or organization including its perceived public reputation and years it has existed" [4].

It continues to be difficult to compare JCIS to the top ranking CIS journals in IF on a number of grounds. Although IEEE Network fell from second to $22^{\text {nd }}$, IEEE still produces four of the top 15 journals ranked according to IF. ACM still produces three of the top 15 journals ranked according to IF, including the $V L D B$ Journal which is ranked second. IEEE and ACM remain very large organizations with over 375,000 and 80,000 members respectively. Combined they produce over 150 publications. Compare this to IACIS with 700 members and two publications.

Challenging the larger organizations in 2007, however, is MIS Quarterly, published by The Management Information Systems Research Center (MISRC), a non-profit organization at the University of Minnesota Carlson School of Management. Obviously name recognition is a large contributor to the impact factor as MIS Quarterly has built a solid reputation as an MIS education focused publication. It is well respected by information systems professors, including JCIS authors who cite it more often than any other journal (besides JCIS). Journal of Web Semantics is also challenging the belief that high IFs only exist for journals with long-standing reputations as it is fairly new to this field, being first published in 2003.

While CIS is not known as one of the more dynamic fields such as medicine or biotechnology in terms of IF, there is a definite shift of emphasis on certain CIS journals from 2003 to 2007 . For a more thorough comparison of CIS journals and especially JCIS, it is still necessary to analyze only those journals on a more sociological level-exploring the reputation and perception of the journal along with organizational size and years in existence. It is also necessary to further explore the emphasis placed on current citations in calculating the impact factor which becomes more evident throughout this study.

\section{Continuing Problems When Using the Impact Factor}

Debate about the IF has been discussed extensively for many years throughout the literature. Seglen offers the most extensive review of the problems associated with the impact factor. These include the premises that "journal impact factors are not statistically representative of individual journal 
articles and correlate poorly with actual citations of individual articles, journal impact factors depend on the research field-small research fields tend to lack journals with high impact, [and] research fields with literature that rapidly become obsolete are favoured" [11]

A number of other authors have extensively explored the problem with the impact factor. Kokko furthers that "only papers published in the Science Citation index are included in impact calculations...books, chapters in books, and non listed journals are thus excluded" [7]. This leads to a reduction in the true accuracy of the impact. Metcalfe further emphasizes that the subject matter of the journal is key to determining its true impact and that journals should definitely not be compared across disciplines [8]. Table 4 illustrates the well-established problems with the IF as previously summarized by Gust in 2005 [4]. It is clear from these problems, that IF should not be used alone when determining a journals relative impact and importance.

\section{Self Citations}

The argument about whether self citations should be included in the IF calculation is one that continues to be discussed and addressed as well. ISI even publishes the number of times a journal cites itself and computes an IF without self citations. For JCIS, these remain high, and do contribute greatly to its rise in IF. For the top CIS journals, however, IF is reduced across all of them when self citations are not counted (see Table 5).

It is a known trend that articles tend to cite more articles from the same journal which can raise their IF. This again is good to note when comparing IFs across journals and disciplines to determine their true impact. Many journals even publish their IF without self-citations as a way to more accurately report their impact.

\section{Citing Journal}

An additional measure tracked by ISI is the number of times individual journals cite a particular journal. This can be very useful in discovering if journals with a higher or lower IF are citing a particular journal, thus raising or perhaps lowering its prominence. Further exploration of the journals citing JCIS and MIS Quarterly show a consistent pattern of the same titles. This is also good to look at when considering a journals reputation and impact in its field as well as across fields. Some of the top journals citing JCIS and MIS Quarterly are European
Journal of Information Systems, Information \& Management, Journal of the Association of Information Systems, and Computers in Human Behavior. This helps demonstrate that JCIS is being cited by and noted by similar publications as MIS Quarterly and vice versa; an indication that JCIS is consistent as being recognized by similar and respectable journals in the field.

The journals citing the other top CIS journals ranked by IF, VLDB Journal and Journal of Web Semantics, did not correlate well with those citing JCIS and MIS Quarterly at all. This is another indication that journals ranked according to IF even within their disciplines can have wide-ranging audiences and topics covered in their journal. A more careful evaluation of individual articles and subjects being referenced would further help delineate those journals consistently publishing on similar subject areas. This could be useful in determining which journals to more specifically compare according to IF or other factors.

\section{The Five-Year Impact Factor: A Better Measure?}

Another essential issue that arises from the impact factor as shown through the literature is the calculation of the IF using only the most recent years. Since "the impact factor is based solely on citation data and only looks at the citation frequency of articles from a journal in their first couple years of publication...journals with articles that are steadily cited for a long period of time (say, 10 years) rather than only immediately lose out with this calculation" [10]. This becomes evident when looking up citation data for older articles and those found in other sources beyond ISI. It is clear that older articles, some as much as 20 years old or more, remain heavily cited. This creates a problem when truly defining a journal's impact as older articles and journals have the opportunity to be cited more often but are not included in the IF calculation $[6,7,8]$. This produces a "subtle bias" and it is suggested that methods to normalize the IF calculation would help to reduce that bias [9]. This is especially true for less dynamic fields, including CIS, where it is evident that its journals are cited more frequently over a longer period of time.

Perhaps then a more accurate factor to look is the Five-Year Impact Factor, which is the average number of times articles from the journal published in the past five years have been cited in the JCR year (2007). It is calculated by dividing the number of citations in the JCR year (2007) by the total number of articles published in the five previous years [12]. 
For JCIS, the Five-Year Impact Factor increases to 0.807 , demonstrating that the range of JCIS influence over the last five years is greater than in recent years (see Table 6).

The Five-Year IF for MIS Quarterly is 9.257; for VLDB Journal, 5.019; and Journal of Web Semantics, N/A since it was not indexed by ISI until 2005. From these numbers, it is clear that the trend in measuring the IF over more years than the most recent two, would be more beneficial as they all show an increase. The same holds true for more well-known dynamic fields such as biochemistry and molecular biology. The top journal's IF in that subject area increases from 31.190 to 33.811 when the Five-year IF is calculated. The less dynamic subject area of mathematics also follows in a similar pattern as its top journal's IF increases from 2.739 to 2.847 .

Once again however, the five-year calculation only computes the cites in a particular year to the previous five years - not overall citations in any given article or total cites overall for a journal. The use of an "adjusted impact factor" has been proposed in various ways but clearly demonstrated by Nisonger who suggests that a calculation of "averaging a greater number of years will reduce the bias's influence" [9]. It is clear from the data that more years need to be included in the calculation to provide a more complete picture as to a journal's breadth and depth of total citations and impact through its history.

\section{Immediacy Index}

Another calculation in JCR that plays a key role in determining the impact of a journal is the immediacy index (II), "a measure of how quickly the average article in a journal is cited" [4]. It is calculated by dividing the number of citations to articles published in a given year by the number of articles published in that year. This was another factor discussed by Gust in 2005 that will be expanded upon using data from 2007. Table 7 compares the immediacy index for JCIS in 2003 and 2007.

In looking at the II for JCIS, it is clear that articles published recently are not being cited quickly and has not changed much since 2003. Among other CIS journals, the top ranked journals have changed somewhat, however, in their rankings, according to II (see Table 8).
The Immediacy Index continues to be not much of a relative factor in relation to CIS journals, as in other disciplines. "Some disciplines are very dynamic, have short publication lags, and produce higher immediacy indexes (as well as IFs) since their articles are quickly cited" [4]. It is more of a measure of which disciplines are very dynamic such as biochemistry and molecular biology which has journals with IFs of over 30 and IIs of over 6 . In contrast, the subject field of mathematics whose journals have IFs of around 2.7 (at the most), have IIs under 0.8 .

Continuing from previous data presented in 2005, as is the case in many disciplines, IF and II do not necessarily correlate. Journal of Database Management ranks $17^{\text {th }}$ in IF, IBM Systems Journal ranks $33^{\text {rd }}$ in IF, and the Journal of the American Medical Informatics Association ranks fifth in IF.

\section{THE GOOGLE FACTOR: OTHER CITATION TOOLS AND MEASURES}

For over 40 years, ISI has held the mantle on citation data. That has rapidly changed over the past several years with the advent of Google Scholar and other online databases that are also providing "cited by" links to its articles. While no journal impact factor is calculated by Google Scholar and these other databases, Chapman presents a study on how ISI is no longer the only source for citation data and that there are a number of other tools to use for journal comparisons [1]. Harzing also presents a study on alternatives to using ISI and the impact factor in assessing journal impact such as Hirsch's Google Scholar h-index [5]. Based upon these findings, it is necessary to go beyond the impact factor and explore these other tools for subsequent citation data analysis.

\section{Google Scholar}

Since its debut in 2004, Google Scholar has promoted both free and subscription access to scholarly articles and publications on the Web. As with ISI, attention must be made to errors, how quickly and regularly it is updated, but "if used with care, it can be used to supplement other sources" such as ISI's citation indices [1]. It can serve as a powerful addition to providing access to citation data and perhaps serve as one even more appropriate for certain journals and fields of study. 


\section{Scopus (Elsevier)}

Scopus, produced by Elsevier, is ISI's most intense rival among subscription citation databases. It boasts to be the "largest abstract and citation database of peer-reviewed literature and quality web sources" [2]. It has references back to 1996 and covers 18,000 titles from 5,000 international publishers.

\section{Business Source Complete (EBSCO)}

With an emphasis on scholarly business information sources, Business Source Complete provides online (via library subscription) access to thousands of scholarly business journals. It also can be used to supplement ISI's citation data as it provides a new feature called "times cited in this database" which links articles to those that have cited them.

\section{ABI/INFORM (ProQuest)}

The other information vendor with a new citation tracking capability is ProQuest which produces numerous databases including ABI/INFORM which focuses on business information journals and publications. Its "cited by" feature also links articles to those that have cited them.

\section{Citation Data Comparisons}

To demonstrate how Google Scholar is perhaps providing more extensive and complete citation data, a quick search of the top three CIS journals ranked by IF, along with JCIS, was conducted in Google Scholar. Using the Advanced Search option, the Journal of Computer Information Systems was searched in the "Return articles published in" search box. The article retrieved with the most citations at the top was "Customer relationship management: an analysis framework and implementation strategies" by Ling, R. (2001) with 92 "cited by" references. In ISI's Web of Knowledge database, the number of times it was cited was only 13. Business Source Complete listed the number of times cited as 11 and ABI/INFORM listed seven "cited by" references. Please note that Scopus could not be searched for comparison as it was unavailable at the time of this study.

Doing the same search in Google Scholar for MIS Quarterly, the top article retrieved "Perceived usefulness, perceived ease of use, and user acceptance of information technology" by Davis, F. (1989) posted 7515 "cited by" references. In ISI, this same article posted 2116 times cited. Business Source Complete listed the number of times cited as
916. ABI/INFORM had no "cited by" data available for this title.

Conducting the same search in Google Scholar for $V L D B$ Journal, the top article retrieved "On matching schemas automatically" by Rahm, E. (2001) posted 158 "cited by" references. It is interesting to note, however, that this article is actually a technical paper. The article version of this paper with a slightly different title of "A survey of approaches to automatic schema matching" only posted 19 "cited by" references according to Google Scholar. In ISI, the article posted 544 times cited. This title is not indexed by Business Source Complete or $\mathrm{ABI} / \mathrm{INFORM}$ so no citation data was available via these databases. In this example, ISI does demonstrate more complete citation data for this article, however, it would be good to investigate further why this title produces fewer cited by references in Google Scholar.

For Journal of Web Semantics, in Google Scholar, the top article retrieved "Automated discovery, interaction and composition of Semantic Web services" by Sycara, K. (2003) posted 425 "cited by" references. This article is not even available in ISI's Web of Knowledge as the database first started coverage for this title in 2005. It is also not indexed in Business Source Complete or ABI/INFORM.

Not accounting for any erroneous citations or duplicates, it is clear that Google Scholar is showing an extensive number of additional citations in comparison to those found in ISI as well as Business Source Complete and ABI/Inform. It is challenging ISI and demonstrating how only "a portion of the total journal universe is covered in the Journal Citation Reports" [10] and remains to have a bias towards English language publications. This becomes even more evident when comparing the number of foreign language publications citing JCIS and other journal articles. A simple scan of references retrieved in Google Scholar shows several foreign language articles not covered by ISI.

It is also very important to note the top cited articles are indeed older articles-from the years 1989 for MIS Quarterly, 2001 for VLDB Journal, 2003 for Journal of Web Semantics, and 2001 for JCIS. Another example of how the impact factor does not take into account the importance and influence of older, more established articles. 


\section{FURTHER IMPACT OF ELECTRONIC PUBLISHING/ACCESS ON CITATION DATA}

The world of journal publishing has rapidly changed in the last five years with access to journals being evermore present in online databases, Google Scholar, and the free Web. As noted above, access to citation data has rapidly changed as well and is no longer only provided via ISI exclusively. It is important to consider how accessible the literature is now when comparing impact factors and other citation measures. "Since journal literature is so much more readily available online through the Web and commercial subscription databases, and therefore can be cited more quickly, it can be expected that the IF and II of a journal will be impacted" [4].

\section{Coverage of Computer Information Systems Journals in Electronic Databases}

The top CIS journals ranked according to IF and II continue to be readily available in online databases, holding true with data provided in 2005 [4]. The top 15 ranked journals are indexed in over 15 databases, except for Journal of Web Semantics which is indexed in only 10 (perhaps because it is relatively new, even though it is ranked so high in IF). The majority of the top 15 are indexed in over 20 databases and some even more than that. MIS Quarterly and a few others with long-standing reputations are indexed in over 50 databases; perhaps another reason why it has such a high IF. With just a few exceptions, most are available in the major online database vendors including EBSCO, Elsevier, Gale, National Library of Medicine, ProQuest, OCLC, H.W. Wilson, as well as Google Scholar.

It is good to note that JCIS is covered by 19 indexes, including Scopus and Google Scholar. This continues to be a positive as it is being well covered by the major article and citation databases, and readily accessible via online access.

\section{CONCLUSIONS}

While the impact factor continues to be a driving force in perceived reputation of journals and their impact on the scholarly community, it remains that "it is necessary to consider many factors such as the true subject nature of the journal, types and length of articles, and size and mission of the publishing organization, in addition to analyzing ISI journal citation data" [4]. Biases in computing the impact factor persist, especially the exclusion of older articles from its calculation and its focus on English language publications. There is a definite cause and need to normalize the impact factor calculation to include older articles as well and more international publications.

ISI has served as a valuable tool to see the progress the Journal of Computer Information Systems has made increasing its impact factor from 2003-2007. It is an established measure that is calculable, however, with the expansion and influence of Google Scholar and other citation databases, research must go beyond the impact factor and traditional ISI data. Other sources must be searched at the article level such as Google Scholar, Business Source Complete, and Scopus. It would be beneficial to conduct a more extensive examination in these databases of individual article citations across the top CIS journals to indeed provide more proof that JCIS and other CIS journals are not being adequately referenced in ISI. Research is also needed to determine the discrepancies in numbers in citations reference across these databases.

Overall, the impact factor for JCIS has increased but the traditional ISI citation data and impact factor calculation fails to adequately measure its complete influence, along with other CIS journals, over time. Further research should be conducted to incorporate older articles and average the number of citations to these over longer periods of time. It would also be worthwhile to investigate how a newer journal such as Journal of Web Semantics can instantly gain so many citations while not being indexed in as many databases as the traditional and long-standing journals.

ISI's impact factor and Journal Citation Reports have led the scholarly publishing field for decades in terms of collecting and analyzing citation data for journals and articles. It has dominated and become the standard in this research, however new products and sources now challenge its reliability and perception as the sole provider of this information. This expansion and update to the 2005 study has opened many other avenues of further research, but has confirmed that impact factors need to be weighed carefully against other considerations and especially now in a world ever progressing with more online access to scholarly information. 


\section{REFERENCES}

1. Chapman, K. (2010). Methods of demonstrating article and journal impact. Journal of Business \& Finance Librarianship, 15(1), 2 - 13.

2. Elsevier B.V. (2010). What does it cover? Retrieved from http://info.scopus.com/scopus-indetail/facts/.

3. Garfield, E. (1972). Citation analysis as a tool in journal evaluation. Science, 178(4060), 471-479.

4. Gust, K. (2005). Evaluating the impact factor: A citation study for information technology journals. Issues in Information Systems, VI(2), 197-203.

5. Harzing, A.W., \& van de Wal, R. (2009). A Google Scholar h-index for journals: An alternative metric to measure journal impact in economics and business. Journal of the American Society for Information Science and Technology, 60(1), 41-46.

6. Holsapple, C. W., Johnson, L. E., Manakyan, H., \& Tanner, J. (1994). Business computing research journals: A normalized citation analysis. Journal of
Management Information Systems, 11(1), 131-140.

7. Kokko, H., \& Sutherland, W. J. (1999). What do impact factors tell us? Trends in Ecology \& Evolution, 14(10), 382-384.

8. Metcalfe, N. B. (1995). Serious bias in journal impact factors. Trends in Ecology \& Evolution, 10(11), 461.

9. Nisonger, T. E. (1994). A methodological issue concerning the use of social-sciences citation index journal citation reports impact factor data for journal ranking. Library Acquisitions-Practice and Theory, 18(4), 447-458.

10. Schroeder, H. (2010). Journal Impact Factors. Retrieved from http://libguides.lib.msu.edu/impactfactors.

11. Seglen, P. O. (1997). Why the impact factor of journals should not be used for evaluating research. British Medical Journal, 314(7079), 498-502.

12. Thomson Reuters. (2010). Journal Citation Reports Help. Retrieved from http://adminapps.isiknowledge.com.proxy1.cl.msu.edu/J CR/help/h_impfact.htm\#impact_factor. 
Table 1. Impact Factor Calculation for JCIS (2003)

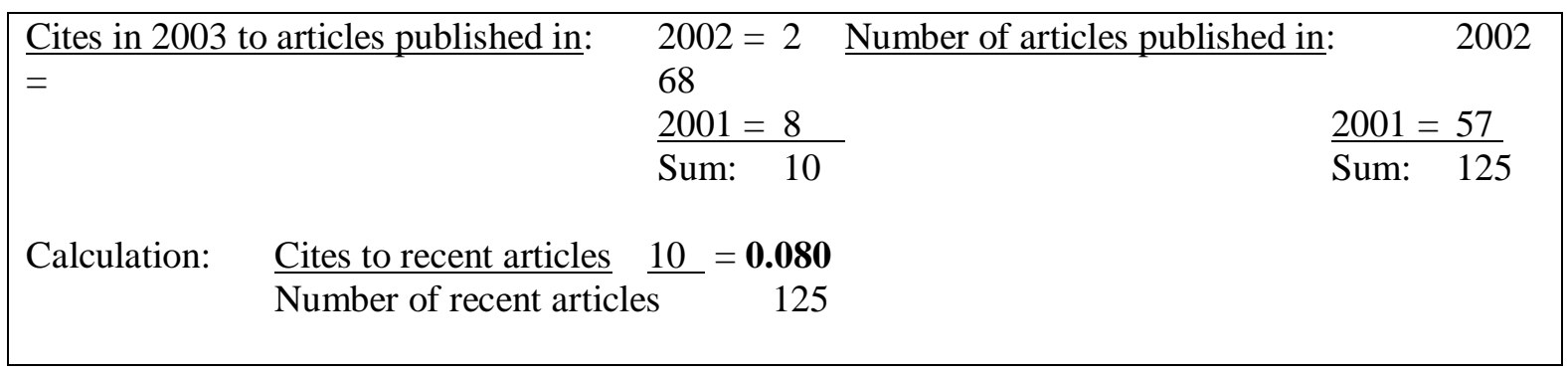

Table 2. Impact Factor Calculation for JCIS (2007)

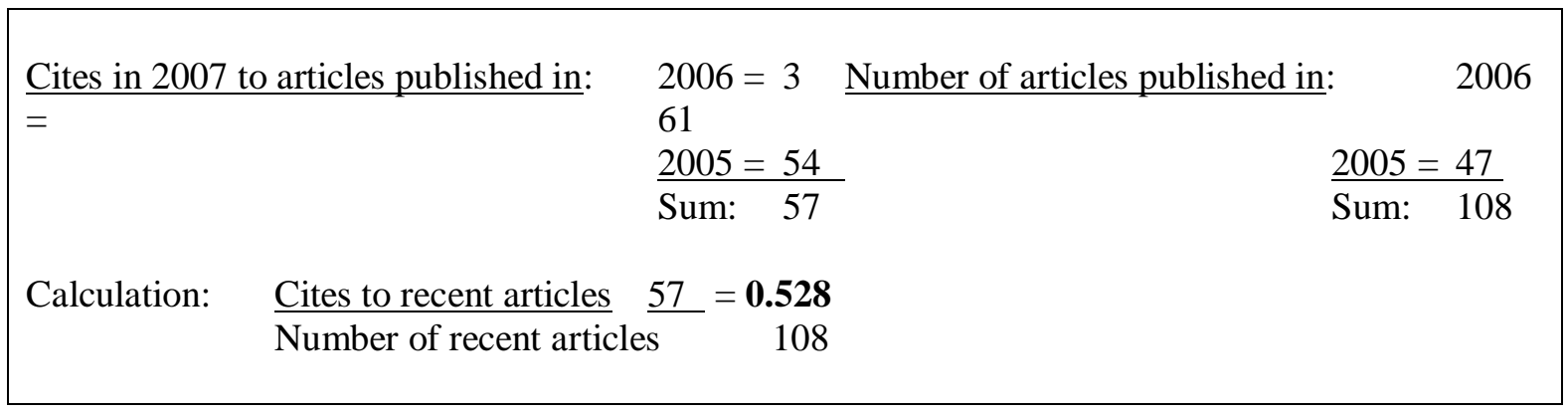

Table 3. Selected CIS Journals Ranked According To Impact Factor (2003 \& 2007)

\begin{tabular}{|l|l|l|l|l|}
\hline $\begin{array}{l}\text { Rank } \\
\mathbf{2 0 0 3}\end{array}$ & $\begin{array}{l}\text { Rank } \\
\mathbf{2 0 0 7}\end{array}$ & Journal Title & $\begin{array}{l}\text { Impact Factor } \\
\mathbf{2 0 0 3}\end{array}$ & $\begin{array}{l}\text { Impact Factor } \\
\mathbf{2 0 0 7}\end{array}$ \\
\hline 1 & 2 & VLDB Journal & 4.545 & 3.818 \\
\hline 2 & 22 & IEEE Network & 3.871 & 1.609 \\
\hline 3 & 13 & ACM Transactions on Information Systems & 3.533 & 1.969 \\
\hline 9 & 1 & MIS Quarterly* & 2.811 & 5.826 \\
\hline N/A & 3 & Journal of Web Semantics* & N/A & 3.410 \\
\hline 77 & 65 & Journal of Computer Information Systems & 0.080 & 0.528 \\
\hline
\end{tabular}

*journal is new to this study—not included in the top three journals ranked by IF in 2003 
Table 4. Continuing Problems with the Impact Factor Calculation

1. Citation Rates of Individual Articles: Because both the highly cited and less-frequently cited articles are included in the IF calculation, articles cited less frequently have equal weight in the calculation.

2. Article Length: Longer articles typically generate many citations and give a higher IF. No corrections are made for the length of the articles cited.

3. Types of Citations: In calculating the IF, citations to letters, editorials, and reports are included in the number of citations to a particular journal (numerator), however only review and research articles are included in the number of recent articles published by the journal (denominator). This can work to inflate the IF of journals with many letters or editorials to those journals that instead have more research articles.

4. Publication Lags \& Exclusion of Older Articles: Since the IF is determined by calculating citations to articles published only within the last two years, those journals with short publication lags allow for more current citations and therefore can lead to a higher IF.

5. Self Citations: Since articles in journals tend to cite articles from the same journal this process of self-citation can lead to more citations and a higher IF, even though other publications may not be citing them as frequently.

6. Author Preferences: An author may or may not choose to publish in a particular journal based upon its IF alone; likelihood of acceptance and refereeing process are other considerations.

Table 5. Self Cites of CIS Journals 2007

\begin{tabular}{|l|l|l|l|l|}
\hline $\begin{array}{c}\text { IF } \\
\text { Rank }\end{array}$ & Journal & Self Cites & $\begin{array}{l}\text { Self Cites to Years } \\
\text { Used in IF } \\
\text { Calculation }\end{array}$ & $\begin{array}{l}\text { IF without Self } \\
\text { Cites }\end{array}$ \\
\hline 1 & MIS Quarterly & $311(7 \%$ of 4329$)$ & $66(16 \%$ of 402$)$ & 4.870 \\
\hline 2 & VLDB Journal & $34(3 \%$ of 1054$)$ & $4(2 \%$ of 168) & 3.727 \\
\hline 3 & $\begin{array}{l}\text { Journal of Web } \\
\text { Semantics }\end{array}$ & $26(7 \%$ of 328$)$ & $4(3 \%$ of 133$)$ & 3.308 \\
\hline 65 & $\begin{array}{l}\text { Journal of Computer } \\
\text { Information Systems }\end{array}$ & $188(65 \%$ of 286$)$ & $44(77 \%$ of 57$)$ & 0.120 \\
\hline
\end{tabular}


Table 6. Five-Year Impact Factor Calculation for JCIS

\begin{tabular}{|c|c|c|c|c|c|}
\hline $\begin{array}{l}\text { Cites in } 2007 \text { to items published } \\
\text { in: }\end{array}$ & $\begin{array}{l}2006 \\
=\end{array}$ & 3 & $\begin{array}{l}\text { Number of items published } \\
\text { in: }\end{array}$ & $2006=$ & 61 \\
\hline & 2005 & 54 & & $2005=$ & 47 \\
\hline & 2004 & 66 & & $2004=$ & 50 \\
\hline & $\begin{array}{l}2003 \\
=\end{array}$ & 54 & & $2003=$ & 59 \\
\hline & $\begin{array}{l}2002 \\
=\end{array}$ & 53 & & $2002=$ & 68 \\
\hline & Sum: & $\begin{array}{l}23 \\
0\end{array}$ & & Sum: & 285 \\
\hline Calculation: & & & & & \\
\hline Cites to recent items & $\underline{230}$ & & $=0.807$ & & \\
\hline Number of recent items & 285 & & & & \\
\hline
\end{tabular}

Table 7. Immediacy Index Calculation for JCIS (2003 \& 2007)

\begin{tabular}{|ll|}
\hline & \\
\hline Calculation: & Cites in 2003 to articles published in 2003 $=\underline{1}=\mathbf{0 . 0 1 7}$ \\
\hline & Number of articles published in 2003 $=59$ \\
\hline & \\
\hline Calculation: & Cites in 2007 to articles published in 2007 $=\underline{0}=\mathbf{0 . 0 0 0}$ \\
\hline & Number of articles published in 2003 $=49$ \\
\hline
\end{tabular}

Table 8. Selected CIS Journals Ranked According to Immediacy Index (2003 \& 2007)

\begin{tabular}{|l|l|l|l|l|}
\hline Rank 2003 & $\begin{array}{l}\text { Rank } \\
\mathbf{2 0 0 7}\end{array}$ & Journal Title & $\begin{array}{l}\text { Immediac } \\
\mathbf{y} \text { Index } \\
\mathbf{2 0 0 3}\end{array}$ & $\begin{array}{l}\text { Immediacy } \\
\text { Index 2007 }\end{array}$ \\
\hline 1 & 2 & IBM Systems Journal & 0.942 & 1.020 \\
\hline 2 & $\begin{array}{l}6 \\
\text { (tied with } \\
\text { MIS Q) }\end{array}$ & $\begin{array}{l}\text { Annual Review Of Information Science } \\
\text { And Technology }\end{array}$ & 0.909 & 0.533 \\
\hline 3 & 3 & $\begin{array}{l}\text { Journal Of The American Medical } \\
\text { Informatics Association }\end{array}$ & 0.794 & 0.699 \\
\hline N/A* & 1 & Journal of Database Management & N/A* & 1.267 \\
\hline 60 & $\begin{array}{l}\text { 80 (tied } \\
\text { with 13) }\end{array}$ & $\begin{array}{l}\text { Journal of Computer Information } \\
\text { Systems }\end{array}$ & 0.017 & 0.000 \\
\hline
\end{tabular}

*journal does not appear in JCR until the 2006 Science Edition. 